\title{
An Examination of the Motivation and Satisfaction of College Students Enrolled in Physical Education Courses
}

\author{
Hsin-Chung CHEN* • David K. STOTLAR**
}

Durpose: The purpose of this study was to find what factor structures
are for the Learning Motivation Scale and Learning Satisfaction Scale, and test a model of learning motivation and learning satisfaction based on college students in Taiwan. Finally, to realize what the most important motivation influence is for students to select PE classes. Methods: The questionnaire was administered by purposeful sampling to 350 students. By using LISREL 8.51 and SPSS 17.0 Package Software, data were analyzed by descriptive statistics, confirmatory factor analysis (CFA), and structural equation modeling (SEM). Results: The results of this study supported a five factor confirmatory factor analysis model of learning motivation as well as a five factor CFA model of learning satisfaction. In addition, the model of learning motivation and learning satisfaction in physical education was supported and the intellectual construct is the most significant motivation to select PE classes. Conclusion: The current study indicated that students' learning motivation significantly affects learning satisfaction in the PE field, although the path coefficient was somewhat low. In other words, from a statistical perspective, there might be some other constructs between learning motivation and learning satisfaction. From a practical perspective, besides letting students feel satisfied with PE classes, the most important values of PE classes are to provide intellectual sport knowledge, to design sport activities which can increase their social relations and an enjoyable atmosphere.

Keywords: Learning Motivation, Learning Satisfaction, Confirma tory Factor Analyses, Structural Equation Modeling

* School of Sport and Exercise Science, University of Northern Colorado, Greeley, Colorado, USA

** School of Sport and Exercise Science, University of Northern Colorado, Greeley, Colorado, USA 


\section{Introduction}

Physical education has often been viewed more in terms of required technical orientation courses with less emphasis on the students' motivations and satisfaction (Chen, Liu, \& Chang, 2008). However, the University Act in Taiwan was modified in 1994 and universities were required to offer more multi-dimensional physical education (PE) classes to students. As a result many universities changed PE classes from required to elective courses. Moreover, the fertility rate in Taiwan declined rapidly over the last two decades, from 1.75\%o in 1986 to $1.03 \%$ in 2009, which was the lowest rate in the world (Taiwanese Ministry of the Interior, 2010). This situation caused some colleges not being able to recruit sufficient students, and also less and less students selected PE classes. Most importantly, the Taiwanese National Policy Foundation (2009) revealed that college students' physical fitness are gradually decreasing and Body Mass Index (BMI) values are soaring. According to the Taiwanese National Policy Foundation (2009), only 32\% of college students do more than 210 minutes of exercise per week.

As a result of these legal, social and other forces, it is necessary to encourage students to take part in sport and take PE classes to improve their physical fitness. Interestingly, Liu and Wei (2009) indicated that a trend is developing for colleges to view students as consumers. Previous studies suggested that it became an important issue to understand college students' learning motivations and satisfaction from a consumer orientation perspective to entice more students to select PE classes (Hong, 2002; Liu \& Wei, 2009). Hence, several principles related to why college students' learning motivation and satisfaction need to be studied are presented. Namely, to view students' motivation and satisfaction for taking PE classes from a sport marketing viewpoint, to sustain high quality physical education, to encourage students to select PE classes to improve their health, to establish exercise habits, and to clarify the contradictory results between previous studies.

\section{Learning Motivation}

Recent research in physical educational settings has found that motivation is a consistent and important contributor to students' functioning and performance (Good \& Brophy, 2000; Hsu, 2010; Huang, 2007). The significance of learning motivation in physical education is understandable and unquestionable (Boiché, Sarrazin, Grouzet, Pelletier, \& Chanal, 2008; Huang, 2007). Learning motives are students' internal factors that arouse and inspire goal-directed learning behavior. Specifically, motives to learn reflect a desire to satisfy internal needs through gaining knowledge and skills in physical education(Boiché et al., 2008; 
Beggs, Elkins, \& Powers, 2005). The college years are important in establishing students' life-long leisure patterns and they are usually also the last period for most students to take PE classes (Beggs \& Elkins, 2010; Hsu, 2010). PE classes can make students partake in activities, increase students' activity frequency and maintain healthy exercise habits. Therefore, it is critical to understand students' motivations for taking PE classes to be able to recruit more students to enroll in such classes. Boiché et al. (2008) pointed out that there are distinct differences between different types of motivation and that this can have a distinct impact on the maintenance and integration of behavior. Hence, the current study investigated the motivation of college students for enrolling in PE classes from multidimensional viewpoints.

The motivation concept that some individuals have multiple motivational orientations has been supported by research (Boiché et al., 2008; Vallerand, 1997). People are intrinsically and extrinsically motivated when they partake in activities for their own benefit or satisfaction. Intrinsic motivation stems from several sources, such as experience stimulation, a lust for knowledge (intellectual factors), wanting to achieve a sense of accomplishment (psychological factors) and a drive to improve oneself (competence factors) (Vallerand, 1997). On the other hand, extrinsic motivation could be external or introspected. If the motivation is external, then the individuals' behavior is controlled by external sources, such as social relations or rewards. But if it is introspected, then individuals have internalized the formerly external source of motivation but have not yet truly accepted the behavior.

Extrinsic motivation, also referred to as self-determination, is represented by two types of regulation, namely identified regulation and integrated regulation (Boiché et al., 2008). Identified regulation refers to a scenario in which people partake because of personal importance, whereas integrated regulation refers to people having incorporated a behavior within their own set of goals and values (physiological factors). From a self-determination perspective, if a student is at the lowest level of self-determination, then he or she has a total lack of motivation. Unmotivated students could feel incompetent because they think they are unable to perform a task and that their performance will not lead to achieving their goals (Deci \& Ryan, 2000).

Development of the Leisure Motivation Scale. Although some research has analyzed students' learning motivation regarding physical education, few researches analyzed this issue from a leisure point of view. Previous studies often researched students' learning motivations from the students' psychological perspective, such as cognitive, affective, value, or self-determination (Boiché et al., 2008; Deci \& Ryan, 2000; Hsu, 2010). For example, Hsu (2010) only selected 
value, expectations, and affective as learning motivation factors to evaluate students' psychological perceptions based on Pintrich, Smith, Garcia, and Mckeachie (1993). Huang (2007) used the Sports Achievement Scale to explore the motivation of students who took PE courses. Motivational factors examined by Huang included: learning objectives, anxiety of examination, motivation of achievement, internal value, and self-expectation. However, Hsu (2010), Huang (2007), and Pintrich et al. (1993) neglected the physiological, social, intellectual and competency factors which a lot of research has considered and stressed on students' motivation in PE courses (Beggs \& Elkins, 2010; Boiché, et al., 2008; Vallerand, 1997).

Furthermore, over time, studies regarding students' learning motivation in the PE field lacked the concept that view students as customers (customer orientation) (Beggs, Elkins, \& Stitt, 2004; Beggs et al., 2005). Beard \& Ragheb (1983) constructed the Leisure Motivation Scale which has been implemented extensively in campus recreational sports. For example, Beggs et al. (2004), Beggs and Elkins (2010), and Starzyk, Reddon, and Friel (2000) explored students' participating motivations in campus recreation by the Leisure Motivation Scale. In addition, Chen (1995) and Beggs et al. (2004) used and modified the research of Beard and Ragheb (1983) by considering cultural factors and modified a scale of college students' motivation for taking PE classes. Therefore, the current study modified the Leisure Motivation Scale (Beard \& Ragheb, 1983) in accordance with previous studies (Chen, 1995; Beggs et al. (2004) and confirmatory factor analysis (CFA) was conducted to examine reliability and validity of responses on the Learning Motivation Scale and to confirm its factor structure.

\section{Learning Satisfaction}

Learning satisfaction is similar to consumer satisfaction. Students need to be satisfied and then they will select PE classes again. Yoshida and James (2010) indicated that the competition in the market, the rise of consumer awareness, and consumer satisfaction have become critical components and useful tools for business. These components can increase customers' repeat purchase intention as well. Kotler (2000) pointed out that the amount of satisfaction depends on how much of an individual's needs are satisfied and the perception about whether the gap between demand and supply has been overcome or not. The smaller the gap the more satisfied, and vice versa. Customer satisfaction can be regarded as a process of psychological comparison between the desire for a previously high level of expectation and the actual experience (Kotler, 2000). In other words, satisfaction is a consumer's immediate response after purchasing products or experiencing services 
Sport satisfaction possesses multiple objectives. Research has demonstrated that students' satisfaction in physical activities during college years has longterm ramifications for constructing their leisure patterns and behavior later in life (Beggs \& Elkins, 2010). Moreover, Shen and Chen (2006) indicated that the students' sport satisfaction may lead to a more positive college experience. Satisfying participation in sports activities during college years greatly enhanced students' college experience by positively impacting their physical, psychological, and social wellbeing. Therefore, having positive and satisfying sports participation experiences not only advances students' physical and mental development, but it has also been shown that this participation is a significant motivator to establish long-term exercise habits. (Beggs \& Elkins, 2010; Hsu, 2010; Yang, Wu, Chen \& Weng, 1997).

Development of the Learning Satisfaction Scale. Currently, the PE field lacks a practical and stable learning satisfaction scale. A useful and stable instrument development is necessary for studying each activity, culture and environment due to the nature of activity-specifics (Beggs, 2002). Thus, the current study viewed the Student Satisfaction Scale (Betz, Klingensmith, \& Menne, 1970) as the major concept to modify the Learning Satisfaction Scale. The Student Satisfaction Scale developed by Betz et al. (1970) is a widely recognized and utilized instrument which is constructed of several factors. It is comprised of six factors that were identified using factor analysis. Namely, (1) policies and programs that affect the students' activities and progress; (2) working conditions related to the physical conditions of students' college life; (3) compensation regarding the amount of study and work required relative to academic achievement; (4) quality of education in terms of an individual's intellectual and vocational development; (5) social life which refers to opportunities to meet socially relevant goals; and (6) recognition which describes the attitude and behavior of faculty and students indicating acceptance of the student as a worthwhile individual.

Recently, Hsu (2010) modified the Student Satisfaction Scale (Betz et al., 1970) in college PE courses. Hsu (2010) derived the concept of teachers' character and quality of teachers from quality of education and derived the concept of facilities from working conditions. Further, she developed the concept of quality of administration from recognition and obtained the construct of social relations from social life. Namely, (1) teachers' character: regarding the instructors' teaching attitudes and competence; (2) quality of teachers: refers to the teaching techniques and ability; (3) facility and equipment: regarding the sports equipment and activity spaces; (4) quality of administration: refers to the attitude and behavior of faculty and convenience of utilizing equipment (5) social relations: regarding the development of friendship, communication skills and team work. However, the current study considered that the constructs of 
teachers' character and quality of teachers are very similar based on their means (4.57/4.40) and standard deviation $(0.49 / 0.56)$ and it might cause multicollinearity problems. Further, the construct of programs is a significant factor (Betz et al., 1970; Beggs \& Elkins, 2010; Beggs et al., 2005), so the current study adjusted the five constructs to quality of teachers, quality of administration, programs, facilities, and social relations in the Learning Scale. Further, CFA was conducted on the Learning Satisfaction Scale to examine its reliability and validity and confirm its factor structure.

\section{Learning Motivation and Learning Satisfaction}

Learning motivation and learning satisfaction are important concepts to understand; however, little research has focused on college students' motivation and satisfaction in physical education classes. Some research has been done regarding college students' leisure motivation and satisfaction in campus recreational sports programs with the findings that motivation can advance college students who are engaging in activities for their inherent satisfaction (Beggs \& Elkins, 2010; Beggs, Elkins, \& Stitt, 2004; Boiché, et al., 2008; Shen \& Chen, 2006). In addition, Boiché et al. (2008) examined how the different types of motivation resulted in different type of gymnastics achievements in high school students. The results revealed that highly motivated students were related to high achievement. However, little attention has been given to examining the relationship between learning motivation and learning satisfaction in the PE class field. It is notable that not only are PE classes important recreational sports programs, but they are also critical to help build students' life-long activity patterns.

Although few previous studies investigated the relationship between learning motivation and learning satisfaction in PE field, the results of these studies were so diverse. For example, Hsu (2010) showed that learning motivation influences learning satisfaction strongly in the PE field. However, Huang (2007) argued that there is no directly significant relationship between learning motivation and learning satisfaction. Huang (2007) indicated that because insufficient factors were included in the construct of learning satisfaction, such as students' perceived performance or quality of teachers, it might have resulted in learning satisfaction not being influenced by learning motivation. Hence, this current study is necessary to examine these two variables in order to define the research gap clearly. The examination of underlying constructs of students' motives and satisfaction through their physical education experiences is needed in order to better comprehend their meanings. 
Most importantly, the learning motivation and learning satisfaction model needs to be examined comprehensively and accurately. Beggs, et al. (2005) suggested that an individual's motivation for participating in sport activities may be related to that person's enjoyment and satisfaction of those sport activities. Nevertheless, Beggs, et al. (2005) only used correlations, t-test and ANOVA to analyze each relationship between each factor and lacked comprehensive understanding of the learning motivation and learning satisfaction model. Therefore, the current study utilized structural equation modeling to construct a learning motivation and satisfaction model to understand and define clearly the relationship between learning motivation and satisfaction. If it were known what motivates students to participate in physical education classes, these experiences could be better understood, and also clarify how those motivations affect a satisfying experience.

\section{Purpose of the Study}

The purpose of this study is to comprehend how students' learning motivation influences learning satisfaction in the PE field and to investigate what the most important motivational construct is to influence students to select PE classes. In particular, the current study aimed to find out if learning motivation has a positive and direct influence on learning satisfaction. The learning motivation and satisfaction model of physical education is shown in Figure 1.

The current study modified the Learning Motivation Scale based on the previous studies (Chen, 1995; Beggs et al., 2004). The Learning Satisfaction Scale was modified based on the previous research (Beggs \& Elkins, 2010; Hsu, 2010). Moreover, the current study tested and confirmed the factor structure for the newly-constructed scale of the Learning motivation and the learning satisfaction.

\section{Research Questions}

1. What is the factor structure for the Learning Motivation Scale?

2. What is the factor structure for the Learning Satisfaction Scale?

3. To investigate if the model of motivation and satisfaction model fits the data.

4. Which construct influences students the most to select PE classes? 


\section{Method}

Participants. According to the Taiwanese Ministry of Education, there were 163 colleges and universities in Taiwan in 2010. Based on the student numbers, they could be separated into large universities (over 9,000 college students), medium universities (between 9,000 and 3,000 college students), and small universities (fewer than 3,000 college students). The total number of college students was 1.24 million (an average of 7,611 at each school) and the gender percentage was $51.86 \%$ male and $48.14 \%$ female, respectively. Because campuses vary in size and in the PE classes offered, the study was conducted at one large university (9,130 students) and two medium universities (6,269 and 5,502 students, respectively). This corresponded to an average of 6,967 per university. Sampling for the current study was conducted in accordance with procedures used by Beggs et al. (2005) and Huang (2007), in which participants included freshmen to seniors, so that students' perceptions across the range of student developmental levels were represented. A total of three PE classes at each university with the widest variety of academic majors was targeted for sampling in order to best represent the student population across a variety of PE classes.

In the current study, the questionnaire was administered to a total sample of 364 students for purposes of testing the structural equation model. After deleting 14 incomplete surveys the final sample for phase two was $\mathrm{N}=350$. As a general rule of thumb, it is adequate to have at least 200 subjects for CFA and SEM. Further, maximum likelihood and estimation methods are the two estimation methods which are applied extensively within SEM. Both maximum likelihood and estimation method require a minimum of 200 samples (Bollen, 2002), so 350 participants were sufficient to conduct CFA and SEM. There was accurate representation in terms of gender $($ Male $=57.1 \%$, Female $=42.8 \%)$ and grade (Freshman $=30 \%$, Sophomore $=44.3 \%$, Junior $=22.6 \%$, Senior $=3.1 \%$ ). Additionally, students were asked to indicate the primary sources of information they consulting to select PE classes. Of the sources selected, $43.8 \%$ received information from schools, $33.7 \%$ of students received the information from classmates, $9 \%$ of students received information from friends, $5.7 \%$ received information from the internet, and 3.7\% received information from instructors. Regarding the participation in PE classes, $94.3 \%$ of students participated in PE classes once a week, $3.1 \%$ twice a week, only $0.6 \%$ thrice a week and nearly $2 \%$ indicated that they participated more than 4 times a week.

The Survey Instrument. The study used survey research to collect data. The questionnaire used in the study is comprised of three sections. To avoid cultural differences and translation confusion influencing the results, the study invited two bilingual professors from the National Taiwan Sport University and one 
bilingual professor from the Taipei Municipal University of Education to translate and discuss prudently the scales before finalizing the questionnaire.

The first section of the questionnaire consisted of the Learning Motivation Scale which was modified based on previous studies (Beard \& Ragheb, 1983; Beggs \& Elkins, 2010; Chen, 1995) and focused on motivational factors for college students in selecting PE classes. This scale contained 15 items that subsumed five factors with three items in each factor. The five factors of the Learning Motivation Scale include: (1) physiological: defined as achieving physical fitness goal, fitness development, and broadening of the activities in which they partake; (2) the psychological factor refers to the psychological benefits of participation, such as enjoyment, relaxation and a joyous class atmosphere; (3) the social factor refers to the need for interactional relationships with other people; (4) the intellectual factor refers to cognitive and rules learning or the opportunity to improve sport skills; and (5) the competence/mastery factor includes items that explain motivation in terms of the desire for competition and challenge. A five-point Likert scale was used to measure items on the LMS (1 = strongly disagree; 5 = strongly agree). According to Beggs and Elkins (2010), Cronbach's $\alpha$ coefficient demonstrated a strong measure of reliability for the motivation measures (0.93).

The second section of the questionnaire consisted of the Learning Satisfaction Scale which was modified based on the previous scale (Beggs \& Elkins, 2010; Hsu, 2010) and focused on satisfaction factors for college students in PE classes. This section contained 15 items that subsumed five factors, each measured by three items. The five factors in the learning satisfaction scale are: (1) quality of teachers which refers to the teachers' teaching attitudes and techniques; (2) quality of administration which refers to the attitudes and behaviors of faculty and convenience of utilizing equipment; (3) the programs factor includes time of classes, competence of faculty and evaluations; (4) facilities measures students' satisfaction with characteristics such as lights, air conditioning and activity spaces; and (5) the social relations factor refers to the development of sportsmanship, communication skills and team work. A five-point Likert scale was used to measure the items ( $1=$ strongly dissatisfied; $5=$ strongly satisfied $)$. According to Beggs and Elkins (2010), Cronbach's $\alpha$ coefficients demonstrated a strong measure of reliability for the satisfaction measures (0.93).

The third section was a demographic section requesting participants' gender, college grade year, the source of information used to select PE classes, and how many times a week they attended PE classes. 
Data Collection Procedures. I contacted the five instructors of the PE class first to obtain their permission to allow me access to their students. Upon receiving permission from the instructors I affirmed the time with the instructors, and then collected the data at the beginning of the PE classes. Directly before the survey, students were explicitly told how to complete the questionnaire, that their answers would not be shown to their instructors and that it was an anonymous survey without correct or incorrect answers. This was done in order to avoid social expectations that might possibly influence the students. Sufficient time of approximately 5 minutes was given to the students to complete the questionnaire

Data Analysis. First, two separate confirmatory factor analyses were conducted using Lisrel 8.51 (Jöreskog \& Sörbom, 2003) in order to examine the factorial structure of the measures assessing students' motivation and satisfaction. CFA was also utilized to examine the reliability and validity of the scale and to affirm the five factors therein. A factor loading above 0.40 is suggested as a reasonable fit (Bentler \& Wu, 1993; Jöreskog \& Sörbom, 2003). Next, structural equation modeling was utilized to test a model positing a direct relation between learning motivation and satisfaction model. For the latent variables of motivation and satisfaction, I created composite scores and use ten subscale scores as indicator variables.

All parameters were estimated by the method of maximum likelihood estimation for CFA and SEM. It is generally recommended that a variety of global fit indices be examined to assess the goodness-of-fit of the structural model (McDonald \& Ho, 2002). $\chi^{2}$ is the most commonly applied statistic indicator. However, since the value of $\chi^{2}$ is affected by the sample size, a large number of participants can cause $\chi 2$ to be inflated when assessing model fit (Hu \& Bentler, 1999). Many researchers have applied the method that divides the value of $\chi^{2}$ by degrees of freedom instead of relying only on the overall $\chi^{2}$ and its associated test of significance (McDonald \& Ho, 2002). Carmines and MacIver (1981) suggested that a $\chi 2 / \mathrm{df}$ ratio of less than 3 is favorable for a large sample. Other statistics such as a non-normed fit index (NNFI), comparative fit index (CFI), root mean square error of approximation (RMSEA) and standardized root mean square residual (SRMR) have also been applied to assess model fit (Jöreskog \& Sörbom, 2003; McDonald \& Ho, 2002). In particular, a NNFI and a CFI value above 0.90 , a RMSEA value of 0.06 and below, a SRMR value of 0.08 and below are all suggested reasonable fit (Browne \& Cudeck, 1993; Byrne, 1998). 


\section{Results}

CFA of Learning Motivation. The learning motivation factor loading of each item is shown in Table 1, together with the composite reliability and average variance extracted. The standardized factor loadings were all significant at the .05 level and ranged between .78 and $.93(\mathrm{M}=.85)$. The composite reliability values of each item were more than .60, which showed that all latent variables illustrated high internal consistency (Bagozzi \& Yi, 1988). Further, the convergent and discriminant validity was evaluated using the average variance extracted, which must be higher than .50 (Bogozzi \& Yi, 1988; Hair, Anderson, Tatham, \& Black, 1998). In the current study, the average variance extracted for all five of the latent variables exceeded .50. The Learning Motivation Scale had adequate convergent and discriminative validity. Factor loadings, composite reliabilities, and average variance extracted are presented along with the corresponding items in Table 1.

The motivation structure was supposed to rely on five factors, namely the following: physiological, psychological, social, intellectual, and competence/ mastery, with three items expected to load on each factor. All parameters were estimated by the method of maximum likelihood estimation. The analysis showed a relatively good fit of the five-factor structure with the data, $\chi^{2}(\mathrm{df}=80)$ $=177.08, \mathrm{p}<.05$, comparative fit index $(\mathrm{CFI})=.95$, non-normed fix index $(\mathrm{NNFI})=.93$, standardized root mean residual $(\mathrm{SRMR})=.03$, root-mean-square error of approximation (RMSEA) $=.07$, and $90 \%$ confidence interval $(\mathrm{CI})$ of RMSEA $=.05-.09$. 
Table 1. Items of the Learning Motivation Scale with Factor Loadings, Composite Reliability, and Average Variance Extracted: "I participate in physical education classes..."

\begin{tabular}{|c|c|c|c|c|}
\hline Factors & Motivation Items & Factor loadings & $\begin{array}{l}\text { Composite } \\
\text { reliability }\end{array}$ & $\begin{array}{l}\text { Average } \\
\text { variance } \\
\text { extracted }\end{array}$ \\
\hline \multirow{3}{*}{ Physiological } & to achieve physical fitness goals & .81 & \multirow{3}{*}{.92} & \multirow{3}{*}{.79} \\
\hline & to broaden the activities I partake in & .92 & & \\
\hline & to develop my fitness ability & .92 & & \\
\hline \multirow{3}{*}{ Psychological } & to enjoy the fun side of sport & .84 & \multirow{3}{*}{.91} & \multirow{3}{*}{.77} \\
\hline & for stress and pressure relief & .93 & & \\
\hline & for the atmosphere on the courts & .87 & & \\
\hline \multirow{3}{*}{ Social } & to gain a feeling of belonging & .85 & \multirow{3}{*}{.89} & \multirow{3}{*}{.73} \\
\hline & to build friendship with others & .91 & & \\
\hline & to meet new and different people & .80 & & \\
\hline \multirow{3}{*}{ Intellectual } & to explore new sport rules and knowledge & .88 & \multirow{3}{*}{.87} & \multirow{3}{*}{.69} \\
\hline & to expand sport skills & .81 & & \\
\hline & to understand sport strategies & .80 & & \\
\hline \multirow{3}{*}{$\begin{array}{l}\text { Competence/ } \\
\text { mastery }\end{array}$} & to excel in it so that others like me & .82 & \multirow{3}{*}{.86} & \multirow{3}{*}{.68} \\
\hline & to gain others' respect & .87 & & \\
\hline & to develop physical skills and abilities & .78 & & \\
\hline
\end{tabular}

Note. The factor loadings indicated CFA standardized factor loadings.

CFA of Learning Satisfaction. The learning satisfaction factor loadings associated with the 15 items and 5 factors are shown in Table 2, as well as the composite reliability and average variance extracted. The factor loadings were all significant at the .01 level and ranged between .75 and $.92(\mathrm{M}=.86)$. All of the composite reliability values were higher than .60 , and the average variance extracted for all the latent variables was higher than .50. The Learning Satisfaction Scale has adequate convergent and discriminant validity (Bogozzi \& Yi, 1988; Hair et al., 1998). Factor loadings, composite reliabilities, and average variance extracted are presented along with the corresponding items in Table 2.

The satisfaction structure was supposed to rely on five factors, namely the following: quality of teachers, quality of administration, programs, facilities, and social relations, with three items expected to load on each factor. All parameters were estimated by the method of maximum likelihood estimation. The analysis showed a relatively good fit of the five-factor structure with the data, $\chi^{2}$ $(\mathrm{df}=80)=172.68, \mathrm{p}<.05$, comparative fit index $(\mathrm{CFI})=.95$, non-normed fix 
index $(\mathrm{NNFI})=.93$, standardized root mean residual $(\mathrm{SRMR})=.05$, root-meansquare error of approximation (RMSEA) $=.08$, and $90 \%$ confidence interval $(\mathrm{CI})$ of RMSEA $=.06-.10$.

Table 2. Items of the Learning Satisfaction Scale with Factor Loadings, Composite Reliability, and Average Variance Extracted

\begin{tabular}{|c|c|c|c|c|}
\hline Factors & Motivation Items & Factor loadings & $\begin{array}{l}\text { Composite } \\
\text { reliability }\end{array}$ & $\begin{array}{l}\text { Average } \\
\text { variance } \\
\text { extracted }\end{array}$ \\
\hline \multirow{3}{*}{$\begin{array}{l}\text { Quality of } \\
\text { teachers }\end{array}$} & Teachers' attitude toward considering students & .89 & \multirow{3}{*}{.92} & \multirow{3}{*}{.80} \\
\hline & Teachers' professionalism & .92 & & \\
\hline & Teachers' teaching attitude & .86 & & \\
\hline \multirow{3}{*}{$\begin{array}{l}\text { Quality of } \\
\text { administration }\end{array}$} & Administrators' service & .83 & \multirow{3}{*}{.85} & \multirow{3}{*}{.65} \\
\hline & The schedule of the classes & .82 & & \\
\hline & The convenience of equipment rental & .78 & & \\
\hline \multirow{3}{*}{ Programs } & The times of the classes & .82 & \multirow{3}{*}{.88} & \multirow{3}{*}{.71} \\
\hline & The teaching approach of the programs & .89 & & \\
\hline & The method of evaluation of the programs & .82 & & \\
\hline \multirow{3}{*}{ Facilities } & The lighting of the facilities & .75 & \multirow{3}{*}{.88} & \multirow{3}{*}{.70} \\
\hline & The air-conditioning of the facilities & .90 & & \\
\hline & The available space of the facilities & .86 & & \\
\hline \multirow{3}{*}{ Social relations } & The development of team work & .86 & \multirow{3}{*}{.90} & \multirow{3}{*}{.75} \\
\hline & The striving for team honor & .90 & & \\
\hline & Community with others & .84 & & \\
\hline
\end{tabular}

Note. The factor loadings indicated CFA standardized factor loadings.

Structure Model. In the current study, the $\chi^{2}(34)=106.43, \mathrm{p}<.05$, and $\chi^{2} /$ df ratio fit the goodness-of-fit of the model. Further, comparative fit index (CFI) $=.94$, non-normed fix index $(\mathrm{NNFI})=.93$, standardized root mean residual $(\mathrm{SRMR})=.04$, root-mean-square error of approximation $(\mathrm{RMSEA})=.07$, and $90 \%$ confidence interval $(\mathrm{CI})$ of RMSEA $=.06-.09$ indicated an acceptable fit of the model.

Relationships among the Constructs. The path diagram for the final model of the learning motivation and learning satisfaction is illustrated in Figure 1. The path analysis revealed that learning motivation affected learning satisfaction directly $(\gamma 11=.12, \mathrm{t}=1.99, \mathrm{p}<.05)$. That is, if college students have stronger motivation, then they tended to be more satisfied with their PE classes. Although the direct 
effect between learning motivation and learning satisfaction is significant, the coefficient of effect is low.

In the learning motivation construct, the coefficients between observed variables and latent variables are factor loadings. The higher the coefficients, the stronger the relationship between observed and latent variables. The higher factor loadings of observed variables can also be explained by the latent variables (Gall, Gall, \& Borg, 2007). In other words, the higher coefficient constructs are the factors which influence students more to select PE classes. The explanation of intellectual factors was the strongest (.86), followed by social (.80), psychological (.73), and competence/mastery (.50) factors. In last position was physiological factor (.46). In the learning satisfaction construct, the constructs which have the higher coefficients are the factors which students emphasize more regarding the components of PE classes. In the construct of learning satisfaction, the explanation of quality of administration (.81) and programs (.81) were the strongest factors. They were followed by social relations (.69) and quality of teachers (.67). The last learning satisfaction factor was facilities (.65).

Figure 1. Learning Motivation and Satisfaction Model of Physical Education

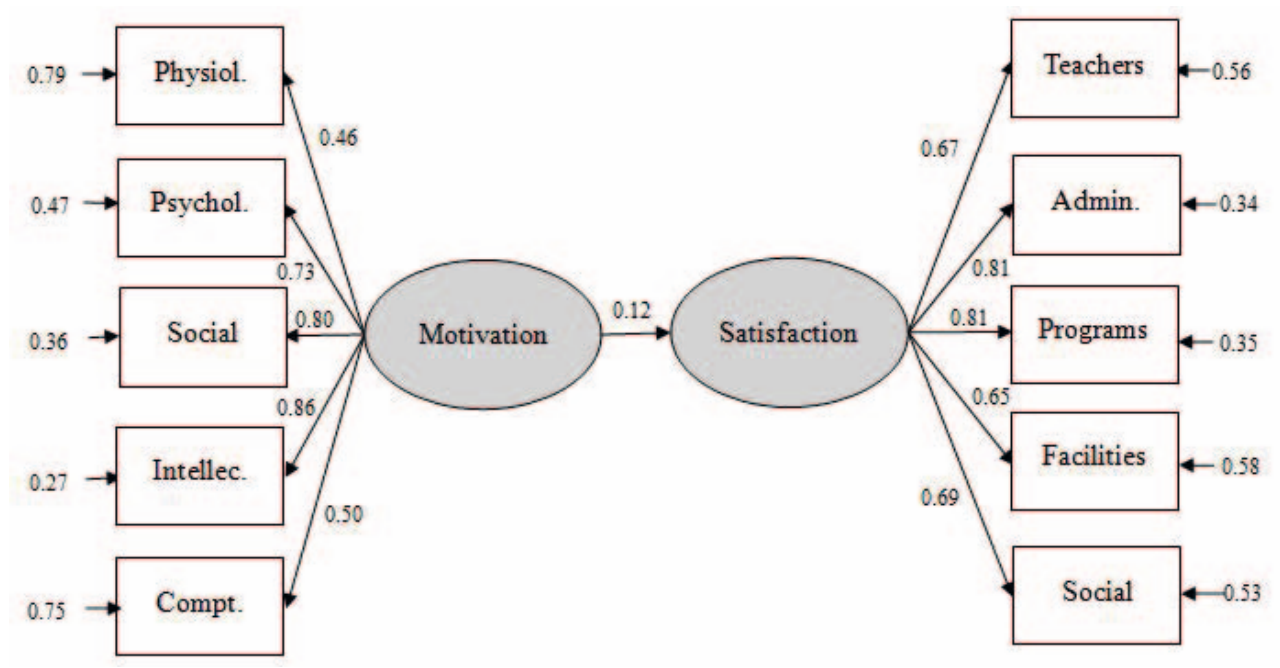

\section{Discussion}

Combining the results of the Learning Motivation Scale in the current investigation with the three studies reported by Beggs et al., (2004), Hsu (2010), 
and Huang (2007) leads to some interesting conclusions concerning college students' motivation in taking PE classes. An examination of the current study reveals that there are five common motives: physiological factors, psychological factors, social factors, intellectual factors, and competence/mastery factors. In accordance with the previous studies (Betz et al., 1970; Chen, et al., 2008; Hsu, 2010), the current study also confirmed five common satisfaction factors: quality of teachers, quality of administration, programs, facilities, and social relations. All composite reliability values of each factor exceeded .60 and all average variance extracted of each factor exceeded .50, which mean the Learning Motivation Scale and the Learning Satisfaction Scale have adequate convergent and discriminative validity. These two scales have adequate reliability and validity to analyze college students' psychology and emotional factors. It is appropriate to predict college students' satisfaction through analysis of students' psychology and emotional factors. The current study provides an understanding of college students' learning motivation and learning satisfaction regarding teachers and administrators in a PE class setting and will assist a deeper conceptualization for future studies regarding PE classes.

To investigate the motivation and satisfaction model. The path analysis of the learning motivation and learning satisfaction model revealed that learning motivation affected learning satisfaction directly $(\gamma 11=.12)$. Namely, when college students put more learning motivation into PE classes, it would result in higher learning satisfaction. However, even though the direct effect between the two variables is significant, the coefficient of the effect is low. The result differs from neither from Huang (2007) nor Hsu's research results (2010). Huang (2007) indicated that there is no significant relationship between learning motivation and learning satisfaction. However, Hsu (2010) pointed out that learning motivation influence learning satisfaction strongly. To investigate the reasons on the practical side, students have been viewed as customers by colleges lately, but after all, colleges are educational institutions geared towards improving students' knowledge, aesthetics, and skills through PE classes. Besides letting students feel satisfied with PE classes, the most important values of PE classes are to raise students' learning effectiveness, to improve students' health, and to maintain healthy exercise habits. Investigating on the research side, the previous research indicated the low coefficient between learning motivation and learning satisfaction being that learning motivation highly affects students' selflearning-satisfaction, such as performance and teaching method perceptions, rather than their entire learning satisfaction, such as quality of administration and facilities (Huang, 2007; Boiché, et al., 2008). However, this current research focuses on their entire learning satisfaction and it might cause the low coefficient. Additionally, according to Hsu's study (2010), learning motivation could strongly affect learning satisfaction through learning effect, so I suggest that more 
variables be added to explore students' learning model, such as learning effect and loyalty to take PE classes, in the future study.

In the learning motivation constructs, the explanation of intellectual factors was the strongest, followed by social, psychological, and competence/ mastery factors. In last position was the physiological factor. The result is slightly different from the result of Beggs et al. (2004) and Beggs, and Elkins (2010). This current result shows that PE classes, after all, still include an educational essence, so students still desire to lean some sport skills, knowledge, and strategies in PE classes. The social factor is also a variable that college students indicated as an important learning motivation variable. This finding is important to consider as many college students choose to take PE classes with fellow students and peers, because they may pursue the PE classes that would provide a social experience with their classmates and peers. Furthermore, we can't ignore the importance of PE classes in providing college students with hours of exercise, so they can achieve physical fitness goals and develop their fitness ability. Sometimes, PE classes also offer some college students opportunities to revel in their high performance sport skills, thus, it is understandable that psychological and competence/ mastery factors are in third and fourth positions of learning motivation. Contrary to these findings, the physiological factor is of the least important in this current study, indicating that the fun side of sport and stress and pressure relief is of lesser importance in learning motivation than the other factors.

\section{Conclusions}

Little attention has been given to examine students' learning motivation and learning satisfaction in PE classes. This current study used, modified and combines the Leisure Motivation Scale (Beard \& Ragheb, 1983) and the Student Satisfaction Scale (Betz et al., 1970), to create the Leaning Motivation Scale and the Learning Satisfaction Scale, which considered multicultural factors and were translated reviewed by three experts in physical education. An examination of the current study displays that there are five common motives in taking PE classes at university/college level: physiological factors, psychological factors, social factors, intellectual factors, and competence/mastery factors. In addition, the current study also confirmed five common satisfaction factors: quality of teachers, quality of administration, programs, facilities, and social relations. Reliability and validity of these two scales have been proved to analyze college students' psychology and emotional factors. A comprehensive concept of college students' learning motivation and learning satisfaction is also provided for teachers and administrators regarding PE class settings and can assist and be extensively applied for deeper conceptualization in future studies regarding PE classes. 
The finding of the current empirical study proved that students' leaning motivation significantly affects learning satisfaction, but that the coefficient of effect is low. Although faculty and marketers hope and strive to improve students' satisfaction through raising learning motivation to let students take PE classes again and maintain students' exercise habits, the results of this study suggest that these efforts may need to be more comprehensive in order to provide more satisfying experiences to those who may be intellectually motivated. Another finding of this study suggests that the desire for learning sport knowledge, sport skills, and sport strategies (intellectual factors) are important motivational factors to all college students. In addition to offering traditional activities that provide physiological challenges in PE classes, teachers and programmers should consider creating knowledgeable and educational activities that provide intellectual benefits or experiences. The other finding of this current study suggests that college students may be seeking a social element in PE classes. The fact that a lot of students partake in campus activities because they are influenced by their peers and thus leads to satisfying experiences must be acknowledged. Additionally, PE program designers should consider assisting a social experience when marketing programs, because the social component is of importance to taking PE classes.

Limitations and Research Perspectives. Because of time and financial limitations, the current study only chose the students of three universities in Taiwan. The sample was a nonprobability sampling designed to be representative of the undergraduate enrollment in PE classes. Generalizability to the population was limited by the nonprobability sampling method, so a probability sampling strategy should be incorporated in coming research designs. In future studies, researchers can collect new data for cross-validation examination. Not only does the research provide a comprehensive and stable concept regarding learning motivation and learning satisfaction models in PE classes, but can also improve predictive validation for the whole model.

Finally, as in many previous studies, some of the relationships observed that we cannot exclude are due to the omission of a relevant variable. For instance, the learning effect provided might have had an impact on students' motivation and satisfaction at the same time. Further studies should nevertheless add and control this variable and use SEM to retest the model. It will help to offer empirical and concrete results for faculty and program designers to develop PE programs. 


\section{References}

Bagozzi, R. P., \& Yi, Y. (1988). On the evaluation of structure equations models. Journal of the Academy of Marketing Science, 16(1), 76-94.

Beard, J. G.., \& Ragheb, M. G. (1983). Measuring leisure motivation. Journal of Leisure Research, 15(3), 219-228.

Beggs, B. A. (2002). Activity satisfaction in golf and simulated golf (Unpublished doctoral dissertation). Indiana University, Bloomington, IN.

Beggs, B. A., \& Elkins, D. J. (2010, July). The influence of leisure motivation on leisure satisfaction. The Cyber Journal of Applied Leisure and Recreation Research. Retrieved from http://larnet.org/2010-02.html

Beggs, B. A., Elkins, D. J., \& Powers, S. (2005). Overcoming barriers to participa tion in campus recreational sports. Recreational Sports Journal, 29(2), 143-155.

Beggs, B. A., Stitt, J. E., \& Elkins, D. J. (2004). Learning motivation of participants and nonparticipants in campus recreational sports programs. Recreational Sports Journal, 28(1), 65-77.

Bentler, P. M., \& Wu, E. J. C. (1993). EQS/Windows user's guide. Los Angeles: BMDP Statistical Software.

Betz, E. L., Klingensmith, J. E., \& Mene, J. W. (1970). The measurement and analysis of college student satisfaction. Measurement and Evaluation in Guildance, 3, 110-118.

Boiché, J. C. S., Sarrazin, P. G., Grouzet, F. M. E., Pelletier, L. G., \& Chanal, J. P. (2008). Students' motivational profiles and achievement outcomes in physical education: A self-determination perspective. Journal of Educational Psychology, 100(3), 688-701.

Bollen, K. A.(2002). Latent variables in psychology and the social sciences. Annual Review of Psychology, 53, 605-634.

Carmines, E., \& McIver, J. (1981). Analyzing models with unobserved variables: Analysis of covariance structures. In G. Bohmstedt \& E. Borgatta (Eds.), Social measurement: Current issues (pp. 61-71). Beverly Hills, CA: Sage. 
Chen, C. C., Liu, C. C., \& Chang, C. M. (2008). The study of correlation between sport enjoyment and learning satisfaction in Physical Education. Taiwan University Physical Education Journal, 13, 37-53.

Chen W. C. (1995). Reliability and validity analysis of college students' motivation scale for participating in sports recreation. Journal of Physical Education and Sports, 4(2), 109-122.

Deci, E. L., \& Ryan, R. M. (2000). The "what" and "why" of goal pursuits: Human needs and the self-determination theory. Psychological Inquiry, 11, 227268. doi:10.1207/S15327965PLI1104_01

Gall, M. D., Gall, J. P., \& Borg, W. R. (2007). Educational research: An introduction (8th ed.). Boston: Pearson Education Inc.

Good, T. L., \& Brophy, J. E. (2000). Looking into classrooms (5th ed.). New York: Longman.

Hair, J. F., Jr., Anderson, R. E., Tatham, R. L., \& Black, W. C. (1998). Multivariate data analysis (5th ed.). New York: Macmillan.

Hong, C. W. (2002). Sport marketing and management strategies applied in physical education classes. Quarterly of Chinese Physical, 16(3), 73-84.

Hsu, F. S. (2010). A study on learning motivation, satisfaction, and effect of college students taking elective swimming course. Journal of Physical Education Fu Jen Catholic University, 9, 66-83.

Hu, L., \& Bentler, P. M. (1999). Cutoff criteria in fix indexes in covariance structure analysis: Conventional criteria versus new alternatives. Structural Equation Modeling, 6(1), 1-55. doi:10.1080/10705519909540118

Huang, R. Y. (2007). The effects of teaching styles, learning motivation, and learning strategies on college students' learning satisfaction in table tennis course. Bulletin of Sport and Exercise Psychology of Taiwan, 10, 15-36.

Jöreskog, K. G., \& Sörbom, J. (2003). Lisrel 8.54: User's reference guide. Chicago: SSI.

Kotler, P. (2000). Marketing management. Englewood Cliffs, NJ: Prentice-Hall Inc.

Liu, H. H., \& Wei, Z. (2009). A study of student recruitment strategies for college leisure and physical education departments. Sports Research Review, 100, 21-28. 
McDonald, R. P., \& Ho, M. H. R. (2002). Principles and practice in reporting structural equation analyses. Psychological Methods, 7, 64-82. doi:10.1037/1082989X.7.1.64

Pintrich, P. R., Smith, D. A. F., Garcia, T., \& Mckeachie, W. J. (1993).

Reliability and predictive validity of the Motivated Strategies for Learning Questionnaire (MSLQ). Educational and Psychological Measurement, 53, 801-813. doi:10.1177/0013164493053003024

Shen B., Chen A. (2006). Examining the interrelations among knowledge, interests, and learning strategies. Journal of Teaching in Physical Education, 25(2), 182-199.

Starzyk, K.B., Reddon, J.R. \& Friel, J.P. (2000). Need structure, leisure motivation, and psychosocial adjustment among young offenders and high school students. Journal of Offender Rebabilitation, 31(1), 163-174. doi:10.1300/J076v31n01_11

Taiwanese Ministry of the Interior (2010). Statistical Yearbook of Interior. Taipei: Taiwanese Ministry of the Interior.

Taiwanese Ministry of Education (2010). Yearbook of Education Statistics. Taipei: Taiwanese Ministry of Education.

Taiwanese National Policy Foundation (2009, April 17). Taiwanese citizens and students'sportparticipation analysis. Taipei: Taiwanese National Policy Foundation.

Tinsley, H. E. A., \& Tinsley, D. J. (1987). Uses of factor analysis in counseling psychology research. Journal of Counseling Psychology, 34, 414-424.

Vallerand, R. J. (1997). Toward a hierarchical model of intrinsic and extrinsic motivation. In M. P. Zanna (Ed.), Advances in experimental social psychology (pp. 271-360). New York: Academic Press.

Yang, C. H., Wu, H.Y., Chen, C.C., \& Weng, S. P. (1997). A study of the relationships between the conducting approaches and student satisfaction of physical education courses. Physical Education Journal, 22, 153-164.

Yoshida M., \& James, J. D. (2010). Customer satisfaction with game and service experiences: Antecedents and consequences. Journal of Sport Management, 24(3), 3 
Hsin-Chung CHEN, Ph.D., School of Sport \& Exercise Science, University of Northern Colorado. He began his research career analyzing sport event management and the relationship between learning motivation and satisfaction in Physical Education Courses. His current research areas include sponsorship effectiveness and sport consumer behavior. He publishes recently in physical education journals and presents at the international sport management conference, sport marketing association conference, and college sport research institute conference. He can be contacted at: hsin-chung.chen@unco.edu.

David K. STOTLAR, Ph.D., serves as the Director of the School of Sport \& Exercise Science at the University of Northern Colorado. He teaches in the areas of sport management and sport marketing. He has had more than 80 articles published in professional journals and has written more than 40 textbooks and book chapters in sport marketing and management. During his career Dr. Stotlar has given over 200 presentations and workshops at national and international professional conferences. $\mathrm{He}$ also serves as a consultant in sport management to various sport professionals; and in the area of sport marketing and sponsorship, to multinational corporations and international sport managers. He can be reached atdavid.stotlar@unco.edu 